A major purpose of the Technical Information Center is to provide the broadest dissemination possible of information contained in DOE's Research and Development Reports to business, industry, the academic community, and federal, state and local governments.

Although a small portion of this report is not reproducible, it is being made available to expedite the availability of information on the research discussed herein. 


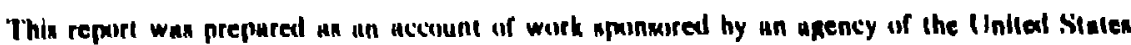
Civernment. Neither thr IInileal Sitales (inovernment nor uny anency therewf, nor any of their

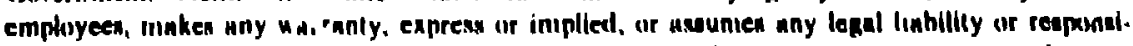
bllity for the uccurncy, comm.'stenew, or usefulness of any information, apparmiun, product, or procean dimloned, or represents that its use would nol infringe privntoly owned righea. Reference lierein lo any specific commerciul product, proweng, of service by irade name, Irademark,

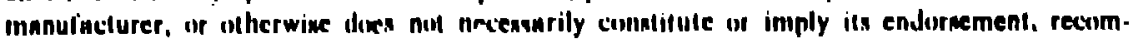

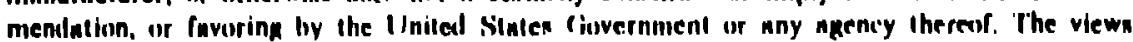
and opinions of auth.ors expreaned herein do nut neceumarlly ninte or refleet thone of the Iniled Silulen (iovernment of uny agency thereul.

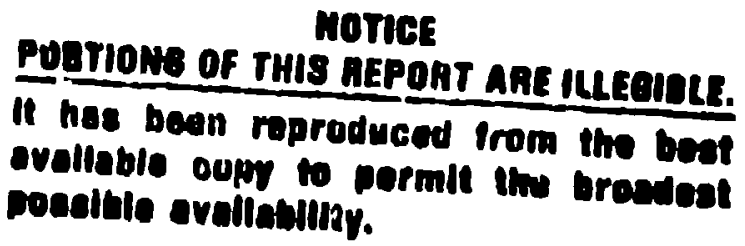

Docember??!, 1983

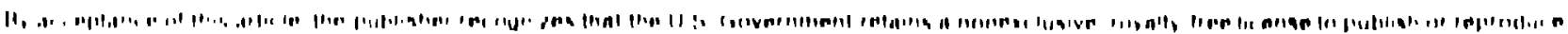

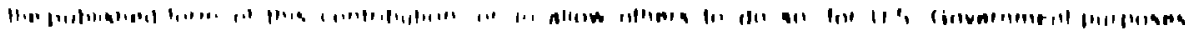

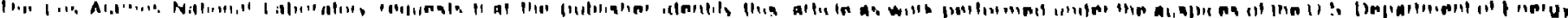


Presented at the Chapman Conference on Magnetic Recunnection, October 3-7, Los Alamos National Laboratory; Panel Discussion.

December 22,1983

\title{
SOLAR FLARES: AN EXTREMUM OF RECONNECTION
}

\author{
by \\ Stirling A. Colgate \\ Los Alamos National Laboratory \\ Los Alamos, New Mexico 87545
}

I will attempt to emphasize three foints.

1. I believe that the solar flare is that particular astrophysical phenomenon that is the exiremum of reconnection. No other phenomenon of which I am aware demands as rapid magnetic flux annihilation as is se'n in the solar flare.

2. Plasma physics experiatents can and should be performed in the laboridtory that model reconnection as we observe it in astrophysics.

3. I helieve that stochastic ficld lines derived from something similar io Al lvon wave curbulence aide a necessary part of reconnection.

We perfo-med experiments some 20 years age al ladwence liveremere laboratory that gave a hint of what 1 believe is happenillg in the rapid reconnerction in moliar flares.

In this panel discussion Biskamp has just made the poidt that w Merel 10 "hreak the topology in the thire dimension to explain recomnection." The"

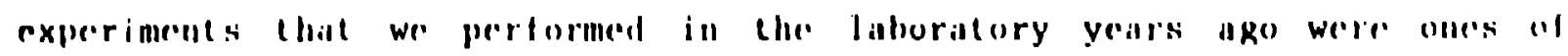
mupping lhe llux surdiacs and showed thit we had hroken just this symurelry: namely, that we llo longer maintained a simple cylindrical geometry but hiel produced a more complicanted one. This is similar to what bill Hones has secen with high-ene:ky porticles in the magnetotail. 


\section{Solar Flare Topology}

Many photographs in optical, EUV, and x-ray wavelengths support the general picture of a twisted loop of flux much like the original picture that Tomny Gold presented for the mechanism of the solai flare. From the magnetic field strength and the density ard temperature derived from the emissivity observed in these loops, it is reasonable to infer that the magnetic field configuration is very nearly force free. It is likely that the twisted flux Lube or force tree field is the basic topology of unstable fields on the sun's surface. However, most modeling of reconnection is donf in the limil simijar to the Petschek mechanism where the fields are exactly opposile at the reconnection layer, i.e., a neutral point or neutral planc as in the magreto tail. The force frec ficlds of the sun, on the other hand, imply a different copology, namely, one where there is a strong magnetic field in the direction of what weuld have becll called "the ignorable coordinate" or the null surface of the models of opposed field reconncetion. The addition of the uniform fieid throughout the opposed field configuration adels a further constraint on t!e fluid motions allowible in recontection as we hilve just heirel reviewed by Biskinup.

Shair and Ficld Topology

Once a mignetio fired is added in ties direcelion of the ignorable

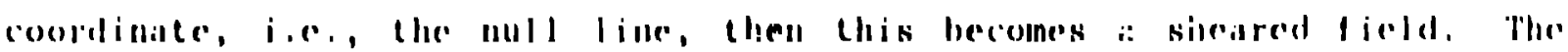
fielel vector rotates as a function of the distance perpendecular lo a flux surfiece. Most frepuently in piasmit astrophysics people have called this

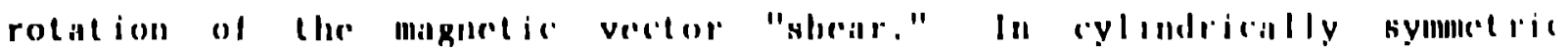
geometry, shear lends to a kradient of the pitch. Pitch is drefined lor an nxisyminetric configuralion as the reciplocial of the mumber of turns ot a

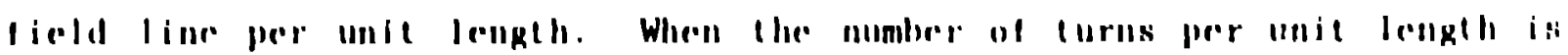


different on each flux surface, then interchanges between two such surfaces is topologically constrained, similar to attempting to "thread" a n!t and bolt of different pitc.. This topol'sgical constraint was originally sought for confinement in thermonuclear fusion plasmas in axisymetric systems. There are axisymmetric configurations of a helical field of constant pitch where, nevertheless, the rield vector rotates as a function of radius. Tlese configurations, "the sciew symmetric pinch: are mos" unstable. in axisymetric fusion plasmas one might produce snear, either by internal plasma currents or external winding currents. In the case of coronal ioops the option of external rigid current carriers is not available and so onc speaks of a force tree field with a plasma current lhat is parallel to the local field vector. This parallel current, Jf, or field aligned current, as referred to in magnetoipheric physics is, loelieve, the origin of the instabilitices that lead to rapid reconnection. This is leccausc ill taboriltory plasma cepperiments the magnitude of this currest was correlated with the case witli which the plasma cscaped a given contiguration. Before discusising the experiment thit loads te this belied, I would like to outline sone of the reasons for searshing for a new and rapid mechanison of recouncetion. This motivation is the hehavior of lhe liagerst and messt ripid solad llaress.

Conditions of the Angust 4, 1072. Solar Flare

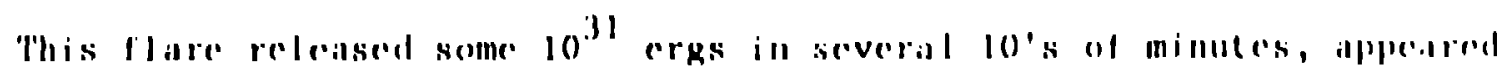

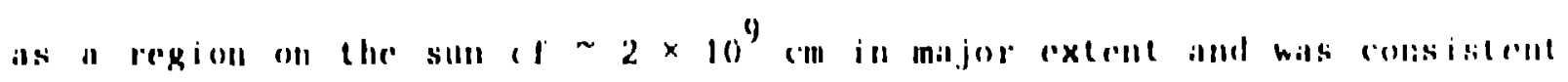

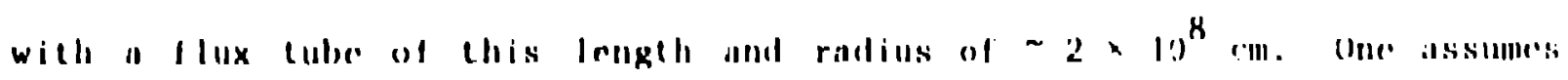

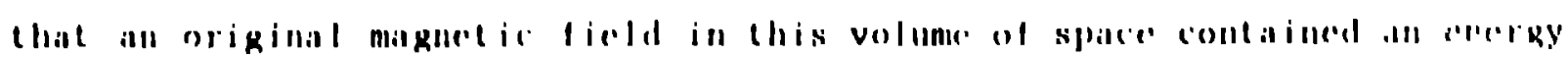

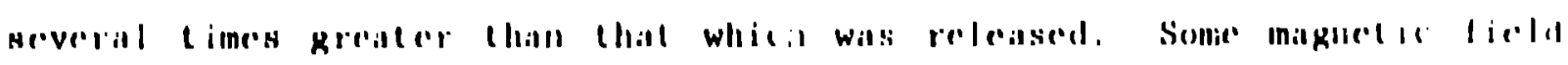

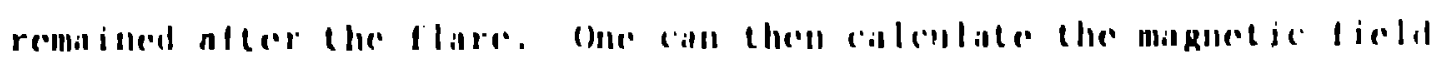


strength such that $B^{2} / 8 \pi=4 \times 1 j^{4}$ ergs $\mathrm{cm}^{-3}$ and find $B$ of the order of a kijogauss. One can also calculkte the inductance of the loop viewed as circuit elcment $2 \times 10^{9} \mathrm{~cm}$ long and return current at 2.5 times the original radius or $\cong 5 \times 10^{8} \mathrm{~cm}$. This is 10 henrys only weakly dependent on geometry. The required paralle? current of a force free field and this inductance necessary to store the released energy beccmes $\cong 4 \times 10^{11}$ amps. This current crates the struss in che magnetic field that is needed to store the released energy. If one interrupts or changes a significant fraction of this current in the characteristic time of the energy release of the $f$ lare, namely $1000 \mathrm{~s}$, then the voltage developed along the coronal loop becomes $(\mathrm{d} / \mathrm{dt})(\mathrm{LI})=5 \times 10^{9}$ volts. If there were a reconnection mechanism that led to a dissipative resistiv ty that could explain the energy releasi and hence clirrent incerruption of such a flare, then very ohviously a fraction of this voltage is availahle for accelerating the particles that are associated with such a flare. The acceleration of these particles is then a contribut on $^{2} 0$ the rosistance.

In particular Linc hard ginnma rays (and neutrous) have been interpreted by Reuven Kanily and Richard lingenfelter as requiring the acceleration of $4 \times 10^{33}$ protons greister than 301050 MeV. If you assume that these proLons are accelerated during $10^{3} \mathrm{~s}$, Lhen this requires a proton current of $7 \times 10^{11}$ amps uhout equal to the current necessiary to maintilin the stored

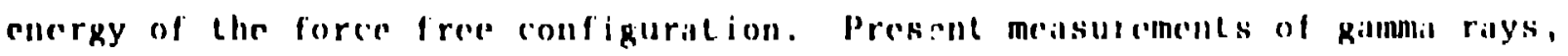

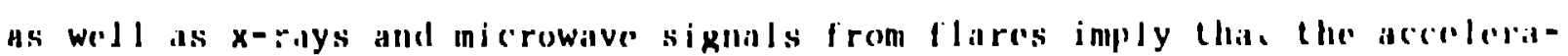
Lion of these pitticles must oceur within less than serveral seconds of time. Such rapid acoeleration makes stochastic, Fermi type icceloration mechanismis very diflicult under these circumstances, hond as a conscyucher, one is strongly induced to associate the accelerition with the celectric fields of 
reconnection or, that is, current interruption. One is further led to the interpretation that almost all the parallel current has somehow been transferred to runaway protcns by a mechanism not yet underatood. The impedence presented to the electron flow aust becowe high enough, presinably due to reconnection, to give rise to the necessary resistance or disgjpation of the current of the flare.

\section{Comparison of Laboratory Experiments and Solar Magnetic Fields}

I wish to compare the mechanism of formation of the magnetic field co.figuration of a solar flare aith the formation of a so-called stabilized pinch in the laboratory. The twisted or helical magnetic field configuration of the stabilized pinch or twisted coronal loop is piedominatly an axial field on the inside and an aximuthal field on the outside. It is the bame magnetic configuration presumed for solar flares; it is also ineasural in the laboratory in the rase of a stabilized pinch. The difference is only one of time-scales because of the raristive diftusivity due to Coulomb collision processes. In the case of ihe solar flare, one starts with the eme:gence of a flux loo, and active region. This flux loop mily or mily not be twisted, and may or may nol have a constant number of turns per unit leflgth during llee period of emergence of rouguly a week. The further thisting of a flux loop can lake plas becouse of the corfolis forice indeced motions of the large scale eddies that are associated with the "fece" ot 11:18 1001).

During the quicucent presumably atable perient of formation, the flux loop emerges from a medium whose pressure is higher than thit ot the field. Alter it emere the relative vacuum of the coroili, the particle firessure is ronfined by the field stress; that is, the pressure Rliadient torcess are revirsed. The diffision taking place dule 10 resistivity will be 
relatively modest because the diffusion coefficient corresponding to a resistivity of a plasma at a 10 to $100-e V$ temperature is relatively small on the space and time scales of a solar flare. For this temperature range the resistive diffusivity is $10^{5}$ to $5 \times 10^{3} \mathrm{~cm}^{2} \mathrm{sec}^{-1}$ corresponding to a resistive age for the loop of $10^{11}$ to $10^{1 / 4} \mathrm{~s}$. Consequently, the fluid motions on the time-scale of weeks can be expected to be represented by the perfect conducivity limit. Therefore, "line tied" motions are expected to accurately represent the topological variations observed. The loop of flux can therefore either be twisted further by the hydrodynamic motions of the surface layers of the sun, or the degree $o_{i}^{-}$twist may be held constant because no further work is performed by the solar flujd mctions.

The Stabilized Pinch or Laooratory Simulation

The laboratory simulation or such a twisted flux tube is performed in an apparalus called a pinch tube. Here, the dimensions are the order of $10 \mathrm{~cm}$ diameter so that in order for a plasma to simulate the profect conductivity limil, the time of formation of the configuration mu:at be less thall the time for the ficlds to diffuse some small fraction of the radius. Typicilly, ons wolld hope to see the field configuration lo be represented by the perfece conductivity approxination for dimonsions greater than a centimeter or $20 \%$ of the ridius. Hense for a diffusion conficient of $100^{5} \mathrm{~cm}^{2} \mathrm{~s}^{-1}$, derived trom a plasma temperature of 13 ov lypical of these experiments, the time-scale of pinch formation must be less than $10^{-5}$ s. Tu form the pinch conligurat:on in this time therefore requires that the

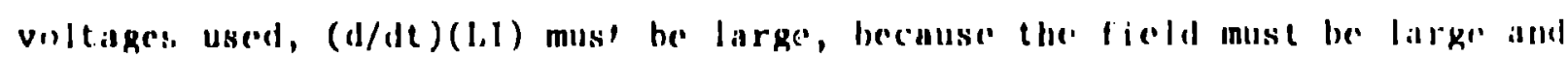
l ime of tormation small. The magnetic field mut be iarge ennugli and piasimal density low enough slleh that the Alfvell specd is high enough such that miny travergals of Alfuén waves can take place duriak the pinch formalion lime. 
This is equivalent to the statement that the formation of the fie'd topology must occur quasi-statically. Typical field strengths are tinen 5000 gauss with particle densitits of $10^{15} \mathrm{~cm}^{-3}$. The Alfvén speed becomes $3 \times 10^{7}$ Cm: $s^{-1}$ and hence the traversal time of sound across the diameter is $1 / 3 \mu \mathrm{s}$. Consequently in this approximation, if the pinch were formed in $5 \mu \mathrm{s}$, the process would be quasi-static in that there would be some 15 traversals of (magnetic) sound or of Alfvén waves across the syslem during the formation process.

The voltage required to "drive" this quasi-static formation process can be derived from the inductance, current, and time. A typical length is $40 \mathrm{~cm}$ so that the inductance becomes $2 \times 10^{-7}$ henrys and the current $=5 \mathrm{RB}$, $\cong 10^{5}$ amps. Consequently the voltage required for the formation of such a configuration in $5 \mu \mathrm{s}$ is $5 \mathrm{kV}$. It is because of this voltage and current. (500 MW) that capacitors are used to form the pinch. The capacitor does nol "drive" plasma insiabilities any more or less than the one-week time scalle for the quasi-static energence and evolution of a solar flarc loop. In this case the energy of the flare is largely developed and stored helow the solar surface before the rlare loop emerges.

Plasma Conditions

The initial laboratory plasma conditions are as iumed quiescent in the sense that the resistivity of the laboratory experiment corresponds to is plasma with a temperalure of roughly $10 \mathrm{eV}$. The plasma number density in the case of the laboritory experiment is such that tale runaway conditiol is marpinilly close to being met. In the case of the solar flare if the topological chatge due to ils emergence occurs in a wopk, the resistive defrusion layer becomes $1.3 \times 10^{4} \mathrm{~cm}$ at $\mathrm{kT}=100 \mathrm{cV}$. This current layer then also mects the runaway condition for an electron density $11=10^{9} \mathrm{~cm}^{-3}$. 
Hence sore local regions of the solar flare should be similar to the laboratory runaway plasma conditions. Therefore, even though a laboratory plasma is "driven" with a capacitor bank it still forms slowly enough to model the quasi-static evolution of a solar flux tube. The microscale phenomenon like plasma oscillations and electron cyclotron periods are so small conpared to the formation time that the laboratory and astrophysical circumstances are similar.

Mapping of Magnetic Flux Tubes in a Laboratory Experiment

In Livermore in the early 60's we (Harold Furth and I) were particularly puzzled that the nested sheared flux surfaces predicted by hydromagnetic theory for the stabilized pinch configuration gave sich exceedingly poor confinement of a plasma. This poor confinement was inferred from the low electron temperatures even in torodial systems. We therefore felt it was necessary to map the flux surfaces to see whether the topological constraint inferred by shear was sumehow or other broken by another phenomenon. Consequently we made a relatively small linear pinch tube, $10 \mathrm{~cm}$ in dianeter and $40 \mathrm{~cm}$ long, and driven by two condenser banks, (1) to form the initijl axial field and (2) a second to form the pinch. In addition, an electron beam probe was used to map the flux surfaces by pulsing a short, $10^{-8} \mathrm{~s}$, intense several amper" and high energy $500 \mathrm{kV}$ electron beam parallel to the magnetic field al various radii. The beam was mapped by the rields ollto il phosphor aud photographed from the opposite end. This is shown in Fig. 1. The mapping of the electron beam at the end plate is essentially an instantaneous mapping of the flux surfaces within the tube. When a rigid copper rod carried the current and the electron baan passed in vacuum, then the flux surfact mapped was indeed the sheared magnetic field expected. The origillal beam circular spot mapped into a short coherent arc. On the other haud when 
a pinch was formed whose radius was roughly half the original, such that the axial field was compressed roughly fourfold and the external $\theta$-field was correspondingly high, then the simple flux surfaces became stochastic as shown in the later pictures, Fig. 1. These flux surfaces became exceedingly distorted very early in time, namely several microseconds. After several more microseconds in time, half way through the rise of the field, the flux surfaces became totrlly tangled so that the high energy electron beam was scattered to the wall in less than the full length of the tube. We inferred from these measurements that for reasons then not understood that the magnetic surfaces were being completely destroyed by an unknown instability. We correlated the strength of this instability with the approach to runaway condition of the current carrying clectrons. At that time and for many years since we have not understood a mechanism whereby the existence of the tangled field alone would cause energy to be fed into the distortion of the fie'd assocjated with it stochasticily. It is my strong conviction that such a feedback mechanism most likely exists. If this is so, then the near runawa condition should escablish the stochasticity that leads to the loss of the more energetic electrons carrying current of the plasillia and hence connect the inside magnetic surfaces with the oulside. The loss of these energetic electrons (or encrgetic ions necessary lo maintain charge nentrality) corresponds to a nel dissination of magnelic field energy and hence Lo reconnection. Such a phenomenon would have a threshold for juitiation associated with runawy that in Lurn may be triggered by a topologica: change induced by magnetohydrodynamic instabilitices. Reconnection should be explored in the laboratory to help to explain it astrophysically.

I am indebted to Albert Petschek for discussions

SAC/rep:62M 

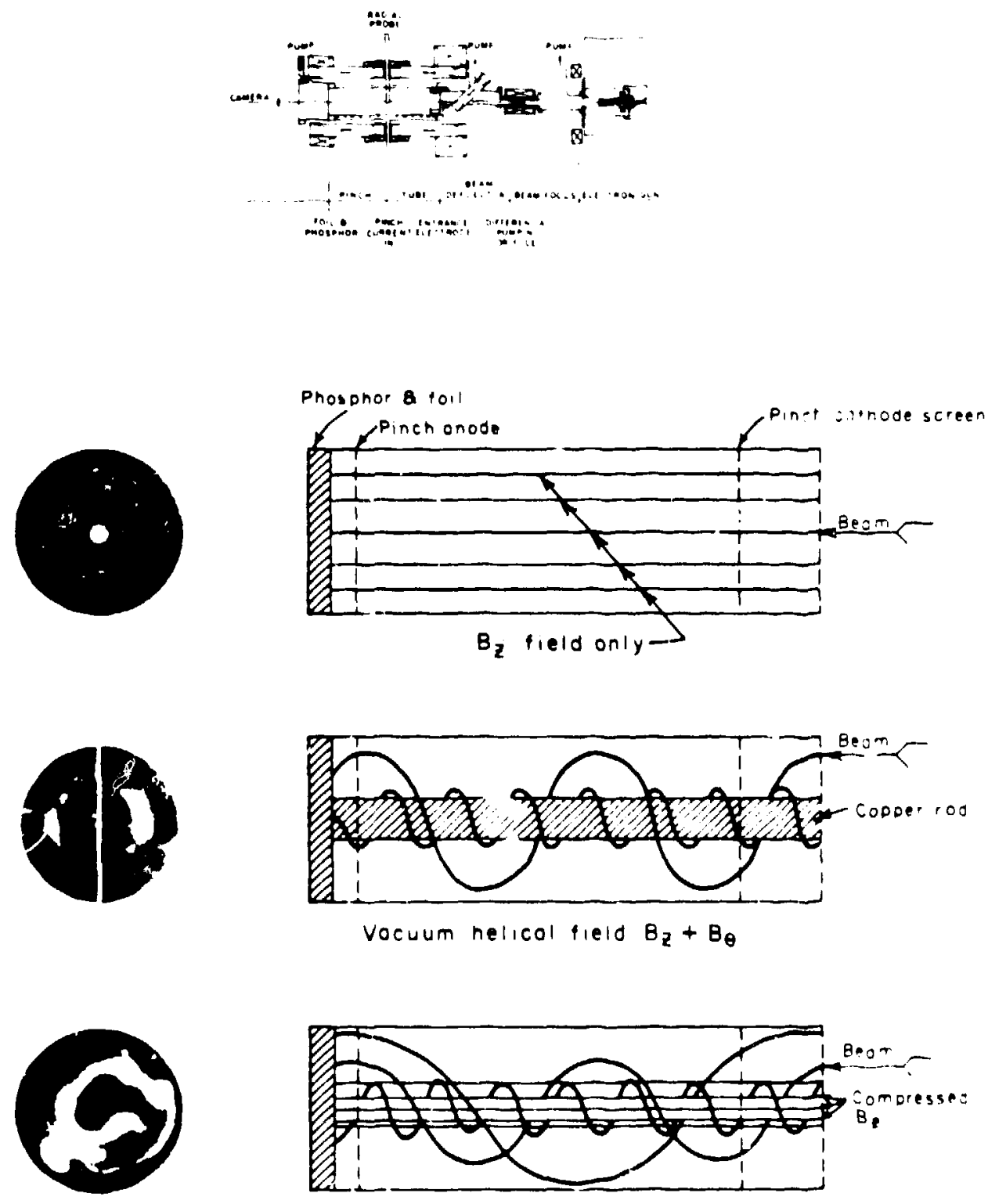

$B_{z}$ Dinch, plasmo current, $J_{11} \simeq 5000 \mathrm{omps} / \mathrm{cm}^{2}$ Time $=48$ microsec
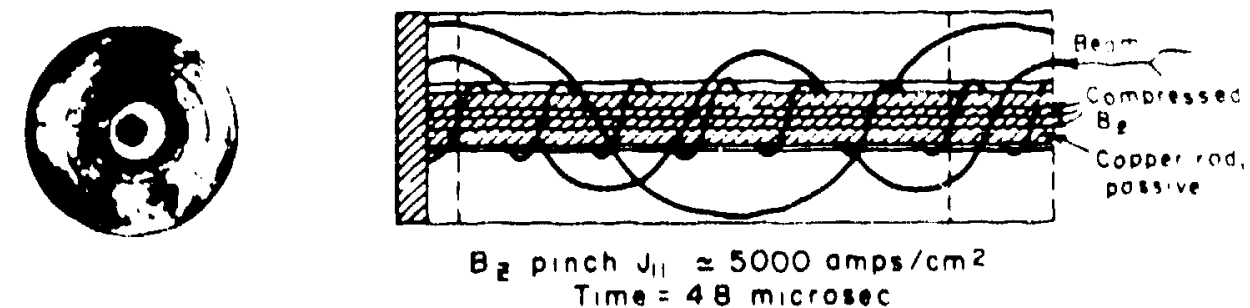

Fici. : The linfar $B$, punch is probed with a pulsed $0.05, \mu s$, high-energy, so) keV, electron gun. The aluminum-coated phowpher beyond the pinsth anode is photogranhed. and the heam nattern is displaved in the insert on the left the

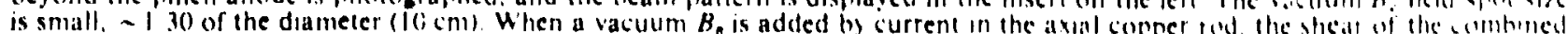

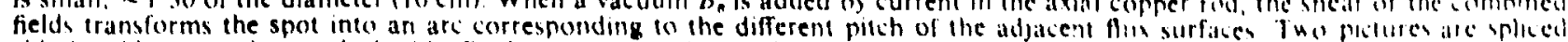

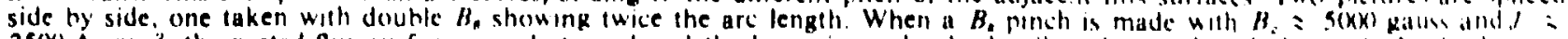

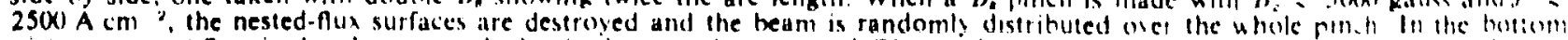
picture, current fow in the plasma equals that in the central copper rod The resultens large sheat partialls stabilues the purch The beam natteus ure the transforms of the tangled magnetic flux. Courtesy of Birdsall et al. (196,2); and Colrat (C, S. A., 1978 , Ap. J. 221, 1068 . 